\title{
Modelling of low-temperature behaviour of cracks in asphalt pavement structures
}

\author{
A. P. S. Selvadurai and M. C. Au \\ Department of Civil Engineering, Carleton University, Ottawa, Ont., Canada K1S 5B6 \\ AND \\ W. A. Phang \\ Research and Development Branch, Pavement and Roadway Office, Ministry of Transportation, \\ Downsview, Ont., Canada M3M 1J8 \\ Received May 24, 1989 \\ Revised manuscript accepted March 13, 1990
}

\begin{abstract}
This paper examines the transient stress analysis of a multilayer pavement structure subjected to heat conduction and associated thermoelastic effects by the cooling of its surface. In particular, the layered structure contains a transverse crack which can be created either during the construction of the pavement or during its service life. The numerical treatment of the transient stress analysis is achieved using a finite element scheme, which models the heat conduction and thermoelasticity of each component in the layered system and the singular stress field at the extremities of a crack. The numerical scheme is applied to examine the manner in which the propagation of an existing crack is influenced by the thermoelastic mismatch between the layers adjacent to the crack location. The analysis also illustrates the influence of the thermoelastic mismatch between a cracked pavement and an overlay, in the suppression of crack propagation.

Key words: fracture mechanics, pavement structures, low-temperature fracture, transient thermal effects, finite element modelling, stress intensity factors.
\end{abstract}

Le présent article traite d'une analyse des contraintes transitoires d'une chaussée multicouche qui a été soumise à la conduction de chaleur et a subi les effets thermoélastiques associés au refroidissement de sa surface. De façon plus précise, le système en couches comporte une fissure transversale créée soit durant la construction de la chaussée, soit durant sa durée de vie utile. Le traitement numérique de 1'analyse des contraintes transitoires est réalisé par la méthode des éléments finis qui permet de modéliser la conduction de chaleur et la thermoélasticité de chaque composante d'une système en couches, ainsi que le champ des contraintes aux extrémités d'une fissure. Le processus numérique est utilisé pour examiner comment les conditions de propagation d'une fissure existante sont influencées par le déséquilibre thermoélastique entre les couches adjacentes à la fissure. L'analyse démontre également l'effet du déséquilibre thermoélastique entre une chaussée fissurée et un recouvrement, dans l'élimination de la propagation des fissures.

Mots clés : mécanique des fissures, chaussées, fissure de température basse, effets thermiques transitoires, méthode des éléments finis, facteurs de l'intensité des contraintes.

[Traduit par la revue]

Can. J. Civ. Eng. 17, 844-858 (1990)

\section{Introduction}

The evaluation and prediction of the performance of asphalt pavement structures subjected to low-temperature effects is of fundamental importance to efficient pavement design. In this regard, the subject of low-temperature cracking of asphalt pavements has received concerted attention over the past three decades (Humphreys and Martin 1963; Haas and Topper 1968; McLeod 1970; Haas 1970; Shahin and McCullough 1972; Carpenter et al. 1975; Carpenter 1976; Carpenter and Lytton 1978). Recent initiatives in terms of a comprehensive assessment of factors influencing low-temperature-induced transverse cracking are summarized in an Asphalt Institute research report (Asphalt Institute 1981). The international conferences on paving in cold areas (PICA 1982, 1984, 1987, 1990) also document recent advances in the modelling, design, field investigation, and laboratory observations pertaining to the initiation and propagation of low-temperature-induced transverse cracking of asphalt pavements. Since the above references contain extensive accounts of literature pertaining to the subject, no attempt will be made to provide a comprehensive bibliography.

Note: Written discussion of this paper is welcomed and will be received by the Editor until February 28, 1991 (address inside front cover).
When an asphalt pavement surface is subjected to sudden cooling, thermal stresses develop in the asphalt layers. The degree to which such stresses manifest depends on the degree of restraint offered by the various components of the pavement structure and their relative thermal and elastic properties. The thermal stresses induced within a pavement structure diminish with time in situations where the asphalt exhibits stress relaxation phenomena. In the low-temperature range, however, the temperature-induced stresses, in general, do not diminish significantly with time. The physical condition and the thermomechanical properties of the asphait layer, therefore, govern the development of low-temperature cracking of the layer (Sugawara et al. 1982). The low-temperature performance of a pavement structure is influenced by a variety of factors. Some of the factors that exert an influence on either the process of transverse crack initiation or its subsequent propagation are classified as follows:

(a) the initial condition of the pavement, defined in terms of density, porosity, permeability achieved in the in situ compacted state, and degree of damage, in terms of micro-cracks, that may be induced during the compaction process;

(b) the thermomechanical properties of the separate phases (i.e., asphalt and aggregates) constituting the asphalt mixture, defined in terms of thermal expansion and contraction properties, heat conduction characteristics, temperature-dependent 
elasticity, viscoelasticity, creep, and strength characteristics of the separate phases;

(c) the thermomechanical properties of the subgrade materials, defined in terms of heat transfer, moisture transfer, and temperature-dependent deformability characteristics of the subgrade materials;

(d) the thermomechanical properties of the asphait composite, defined in terms of thermal expansion and contraction properties, heat conduction characteristics, temperature-dependent elasticity, viscoelasticity, creep, and strength characteristics of the compacted asphalt;

(e) the thermomechanical properties of the interfaces, defined in terms of elasticity, creep, and frictional and delamination strength characteristics of the various interfaces encountered in the pavement structure;

(f) transient thermal effects, defined in terms of daily or seasonal variations (especially rates of change) in the surface temperature of the pavement structure;

(g) transient loading effects, defined in terms of loading patterns consistent with traffic-induced static and dynamic loads;

(h) degradation phenomena, defined in terms of cracking in the asphalt pavement structure, delamination at the asphalt layer and sub-base interface, embrittlement of the asphalt, etc.

A rigorous treatment of all of the above factors, with a view to predicting the time- and temperature-dependent occurrence and propagation of transverse cracking in an asphalt layer, is an extremely difficult task. Even if the mathematical modelling of the process involved can be accomplished, the determination of specific material functions, which are required for engineering use of such models, presents a complicated exercise in materials testing. Prior to considering such comprehensive and all-encompassing models that attempt to predict transverse cracking phenomena, it is instructive to identify certain plausible elementary models which contain salient features about the propagation of existing flaws in a damaged asphalt layer.

This paper focuses on the transient stress analysis of a pavement structure subjected to heat conduction and associated thermoelastic effects. The thermoelastic modelling of asphalt pavements is, of course, a relatively elementary model of the thermomechanical behaviour of asphalt materials subjected to the range of temperatures encountered in a pavement structure, especially to that leading to the low-temperature environment. It is meant to serve as a preliminary study which will be extended, in future investigations, to accommodate complete thermoviscoelastic or thermoviscoplastic constitutive responses. The numerical analysis of the transient thermoelastic effects is performed using the finite element method. Transient effects occur by virtue of time-dependent temperature fluctuations at the surface of the pavement structure. In modelling damaged pavements, account is taken of surface cracks that are already present in the surface asphalt layer and (or) within a newly placed overlay. The numerical analysis of damaged pavements focuses on the evaluation of timedependent stress intensity factor(s) at the crack tips. This is a measure of the energy released while propagating the crack further. The fracture criterion for the propagation of the crack can be assessed in relation to a critical stress intensity factor, which may be derived experimentally. At critical conditions, the stress intensity factor is a measure of the fracture toughness of the material. It should be noted that the paper addresses the problem related to the mechanics of a crack that is present in the layer during thermal loading. The actual process of initiation of such cracks in intact pavement structures is important and is relegated to further studies.

\section{Fundamental equations}

We consider the class of classical coupled-thermoelastic problems, which have been treated quite extensively in the literature in solid mechanics (see, for example, Kovalenko (1969) and Carlson (1972)). The displacement equations of equilibrium governing the thermoelastic problem for a region $D$ are given by

$$
(\lambda+\mu) u_{i, l i}+\mu u_{i, l l}-\beta T_{, i}=\rho \ddot{u}_{i} ; \quad x_{i} \in D
$$

where $\lambda$ and $\mu$ are the isothermal values of Lamé's constants, $\beta$ is the thermoelastic coefficient, $\rho$ is the mass density, and $u_{i}$ and $T$ are respectively the unknown displacement and temperature fields which are functions of position, $x_{i}$, and time, $t$. The subscripts indicate directions $x, y, z(1,2,3)$, and repeated indices are summed over the range of subscripts. The dot indicates a time derivative and a comma indicates a partial derivative with respect to the spatial variables. The general heat conduction equation, which includes the heat source (or sink) term due to mechanical effect, can be written as

$$
\left(k T_{, i}\right)_{i}-\rho c \dot{T}-\left(T-T_{0}\right) \beta \dot{\epsilon}_{l l}+Q=0 ; \quad x_{i} \in D
$$

where $k$ is the coefficient of thermal conductivity, $c$ is the specific heat, $Q$ is the heat source term other than that due to mechanical effect, and $T_{0}$ is the initial temperature distribution when the medium is unstrained. The linearized strain tensor is defined by

$$
\epsilon_{i j}=\frac{1}{2}\left(u_{i, j}+u_{j, i}\right)
$$

and the linear thermoelastic stress-strain relationship takes the form:

$$
\text { [4] } \quad \sigma_{i j}=C_{i j k l} \epsilon_{k l}-\beta\left(T-T_{0}\right) \delta_{i j}
$$

where $\delta_{i j}$ is Kronecker's delta function. It may be noted that for an isotropic elastic material, $C_{i j k i}=\left(\lambda \delta_{i j} \delta_{k l}+\mu \delta_{i l} \delta_{j k}+\right.$ $\left.\mu \delta_{i k} \delta_{j l}\right)$. In situations where mechanical deformations induce little change in the temperature of the body, the thermoelastic term in [2] is 0 , that is, $\left(T-T_{0}\right) \beta \dot{\epsilon}_{l l}=0$. We shall also restrict our attention to the class of quasi-static thermoelastic problem in which the inertia term in [1] can be neglected, that is, $\rho \ddot{u}_{i}=0$.

The reduced forms of the governing differential equations [1] and [2] are subjected to the following boundary and initial conditions. The boundary conditions for the heat conduction problem are

$$
\begin{aligned}
& \text { [5] } \quad T=\bar{T}, \quad x_{i} \in S_{1} \\
& \text { [6] } k \frac{\partial T}{\partial \underline{\sim}}=\bar{q}, \quad x_{i} \in S_{2}
\end{aligned}
$$

where $\bar{T}$ is the temperature on the surface $S_{1}, \bar{q}$ is the rate of heat loss at the boundary $S_{2}, n$ is the outward unit normal to $S_{2}$, and $S_{1} \cup S_{2}$ corresponds to the surface $S$ of $D$.

For the elastic problem, the boundary conditions are

$$
\begin{array}{ll}
\text { [7] } u_{i}=\bar{u}_{i}, \quad x_{i} \in S_{3} \\
{[8] \quad \sigma_{i j} n_{j}=\bar{P}_{i}, \quad x_{i} \in S_{4}}
\end{array}
$$


where $\bar{u}_{i}$ corresponds to the boundary displacement on $S_{3}, \bar{P}_{i}$ are the boundary tractions on $S_{4}$, and $S_{3} \cup S_{4}$ corresponds to the surface $S$ of $D$. The initial temperature in the body is set equal to $T_{0}$. Also, the parameter $\beta$ can be expressed in terms of the isotropic elastic constants, $\lambda$ and $\mu$, and the coefficient of thermal expansion, $\alpha$, as follows:

[9] $\beta=(3 \lambda+2 \mu) \alpha$

\section{Finite element modelling}

The solution of the equations of transient thermoelasticity described in Sect. 2 can be approached in many ways. These include analytical methods based on integral transform techniques and numerical methods based on finite difference, finite element, and boundary integral equation techniques. In view of the finite geometries associated with the modelling of the pavement structures and the crack regions present in such regions, it is convenient to adopt a numerical method of stress analysis based on a finite element formulation. In particular, a Galerkin finite element technique is adopted in the development of the numerical procedures.

\subsection{The Galerkin formulation}

In the quasi-static thermoelastic problem, the thermal and the elastic problems can be considered independently. Therefore, $\delta T$ and $\delta u_{i}$ can be considered as the variation functions, for the problem defined in the previous section, and the corresponding Galerkin expressions can be written as

$$
\int_{D} \delta T\left[\left(k T_{, i}\right)_{, i}-\rho c \dot{T}\right] \mathrm{d} D=\int_{S_{2}} \delta T\left(k \frac{\partial T}{\partial n}-\bar{q}\right) \mathrm{d} S
$$

and

[11]

$$
\int_{D} \delta u_{i}\left(\sigma_{i j, j}-b_{i}\right) \mathrm{d} D=\int_{S_{4}} \delta u_{i}\left(P_{i}-\bar{P}_{i}\right) \mathrm{d} S
$$

respectively. Integrating by parts once the first term of [10] and [11], we obtain

$$
\int_{D}\left[k \delta T_{, i} T_{, i}+\rho c \delta T \dot{T}\right] \mathrm{d} D-\int_{S_{2}} \delta T \bar{q} \mathrm{~d} D=0
$$

and

$$
\int_{D}\left[\delta \epsilon_{i j} \sigma_{i j}+\delta u_{i} b_{i}\right] \mathrm{d} D-\int_{S_{4}} \delta u_{i} \bar{P}_{i} \mathrm{~d} S=0
$$

Equation [13] can be written as

$$
\text { [14] } \begin{aligned}
\int_{D}\left[\delta \epsilon_{i j} C_{i j l m} \epsilon_{l m}+\delta u_{i} b_{i}+\delta \epsilon_{i j} \beta(T-\right. & \left.\left.T_{0}\right) \delta_{i j}\right] \mathrm{d} D \\
& -\int_{S_{4}} \delta u_{i} \bar{P}_{i} \mathrm{~d} S=0
\end{aligned}
$$

Equations [12] and [14] are the required variational expressions for the finite element discretization. Consequently, they can be written in a discretized form as

$$
\begin{aligned}
\sum_{e}\left\{\int_{F_{e}}\left[k \delta T_{, i} T_{, i}+\rho c \delta T \dot{T}\right] \mathrm{d} D\right. & \\
& \left.-\int_{F_{e} \cap S_{2}} \delta T \bar{q} \mathrm{~d} S\right\}=0
\end{aligned}
$$

and
[16] $\sum_{e}\left\{\int_{F_{e}}\left[\delta \epsilon_{i j} C_{i j l m} \epsilon_{l m}+\delta u_{i} b_{i}+\delta \epsilon_{i j} \beta\left(T-T_{0}\right) \delta_{i j}\right] \mathrm{d} D\right.$

$$
\left.-\int_{F_{e} \cap S_{4}} \delta u_{i} \bar{P}_{i} \mathrm{~d} S\right\}=0
$$

respectively, where $F_{e}$ is an element such that

[17] $D=\sum_{e} F_{e}$

For two-dimensional problems, one can use the following representations:

[18] $T=\left[N_{T}\right]\{T\}_{e}^{n}$
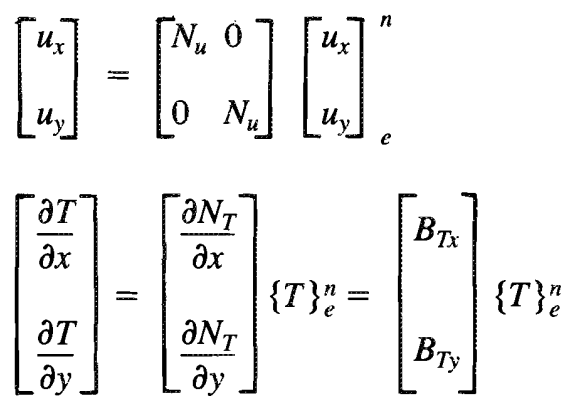

and

$$
\left[\begin{array}{l}
\epsilon_{x x} \\
\epsilon_{y y} \\
\epsilon_{x y}
\end{array}\right]=\left[\begin{array}{cc}
\frac{\partial N_{u}}{\partial x} & 0 \\
0 & \frac{\partial N_{u}}{\partial y} \\
\frac{\partial N_{u}}{\partial y} & \frac{\partial N_{u}}{\partial x}
\end{array}\right]\left[\begin{array}{l}
u_{x} \\
u_{y}
\end{array}\right]_{e}^{n}=\left[\begin{array}{cc}
B_{u x} & 0 \\
0 & B_{u y} \\
B_{u y} & B_{u x}
\end{array}\right]\left[\begin{array}{l}
u_{x} \\
u_{y}
\end{array}\right]_{e}^{n}
$$

Equations [15] and [16] can be written as

$$
\sum_{e}\{\delta T\}_{e}^{* n}\left[\left[K_{T T}^{e}\right]\{T\}_{e}^{n}+\left[M_{T T}\right]^{e}\{\dot{T}\}_{e}^{n}-\left\{P_{T}\right\}_{e}^{n}\right]=0
$$

and

$$
\begin{aligned}
& {[23] \sum_{e}\left[\begin{array}{l}
\delta u_{x} \\
\delta u_{y}
\end{array}\right]_{e}^{* n}\left[\left[K_{u u}^{e}\right]\{u\}_{e}^{n}+\left[K_{u T}^{e}\right]\left[\{T\}_{e}^{n}-\left\{T_{0}\right\}_{e}^{n}\right]\right.} \\
&\left.-\left\{P_{u}\right\}_{e}^{n}\right]=0
\end{aligned}
$$

respectively. Also, \{\}$^{*}$ indicates the transpose of the matrix. After summation and considering the variations, we obtain

$$
\left[K_{T T}\right]\{T\}+\left[M_{T T}\right]\{\dot{T}\}=\left\{P_{T}\right\}
$$

and

$$
\text { [25] }\left[K_{u u}\right]\{U\}+\left[K_{u T}\right]\{T\}=\left\{P_{u}\right\}
$$

where the global matrices are

$$
\begin{aligned}
& {\left[\left[K_{T T}\right] ;\left[K_{u u}\right] ;\left[M_{T T}\right] ;\left[K_{u T}\right] ;\left\{P_{T}\right\} ;\left\{P_{u}\right\}\right]} \\
& \quad=\sum_{e}\left[\left[K_{T T}^{e}\right] ;\left[K_{u u}^{e}\right] ;\left[M_{T T}^{e}\right] ;\left[K_{u T}^{e}\right] ;\left\{P_{T}\right\}_{e}^{n} ;\left\{P_{u}\right\}_{e}^{n}\right]
\end{aligned}
$$

The element matrices and vectors are

[27] $\left[K_{T T}^{e}\right]=\int_{F_{e}} k\left[B_{T}\right]^{*}\left[B_{T}\right] \mathrm{d} D$ 

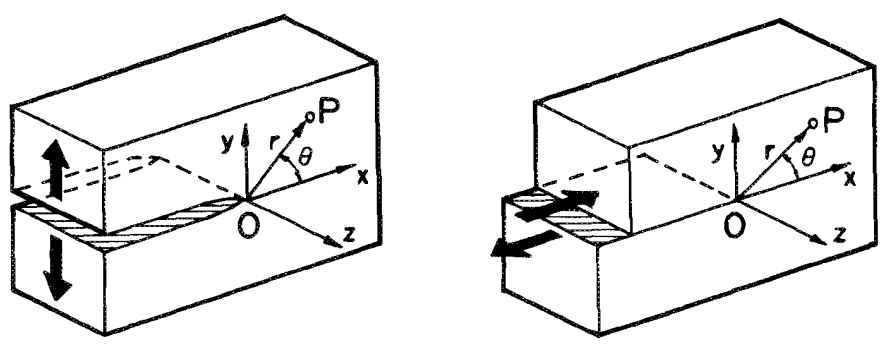

FIG. 1. Flaw opening and flaw shearing fracture modes.

[28]

$$
\left[K_{u u}^{e}\right]=\int_{F_{e}}\left[B_{u}\right]^{*}[C]\left[B_{u}\right] \mathrm{d} D
$$

[29] $\left[M_{T T}^{e}\right]=\int_{F_{e}} \rho c\left[N_{T}\right]^{*}\left[N_{T}\right] \mathrm{d} D$

[30]

$$
\left[K_{u T}^{e}\right]=\int_{F_{e}} \beta\left[\bar{B}_{u}\right]^{*}\left[N_{T}\right] \mathrm{d} D
$$

[31] $\left\{P_{T}^{e}\right\}=\int_{F_{e} \cap S_{2}}\left[N_{T}\right]^{*} \bar{q} \mathrm{~d} S$

and

$$
\left\{P_{u}^{e}\right\}=\int_{F_{e} \cap S_{4}}\left[N_{u}\right]^{*}\{\bar{P}\} \mathrm{d} S-\int_{F_{e}}\left[N_{u}\right]^{*}\{b\} \mathrm{d} D
$$

where

$$
\left[\bar{B}_{u}\right]=\left[\begin{array}{l}
B_{u x} \\
B_{u y}
\end{array}\right]
$$

This completes the formal finite element development of the coupled matrix equations governing the temperature and displacement fields within a finite element domain.

\section{Time integration and iterative schemes}

To obtain the recurrence relations for the time domain of [24], we can apply the scheme proposed by Zienkiewicz (1977):

$$
\{\dot{T}\}=\left[\left\{T_{t+\Delta t}\right\}-\left\{T_{t}\right\}\right] / \Delta t
$$

and

$$
\text { [35] }\{T\}=(1-f)\left\{T_{t}\right\}+f\left\{T_{t+\Delta t}\right\}
$$

where $\Delta t$ is a time step and $f$ is the weighting factor such that $0<f<1$. Therefore, [24] can be expressed as

$$
\text { [36] } \begin{aligned}
{\left[\left[M_{T T}\right]+f \Delta t\left[K_{T T}\right]\right] } & \left\{T_{t+\Delta t}\right\}=\left\{P_{t}\right\} \Delta t \\
- & {\left[\left[M_{T T}\right]+(1-f) \Delta t\left[K_{T T}\right]\right]\left\{T_{t}\right\} }
\end{aligned}
$$

The general expression for the equilibrium equation can be written as

$$
\left[K_{u u}\right]\left\{u_{t+\Delta t}\right\}^{i+1}=\left\{P_{u}\right\}-\left[K_{u T}\right]\left\{T_{i+\Delta t}\right\}^{i}
$$

where $i$ is the iteration number. An example for the need for iterating [37] is the possibility of separation at the interface of two different materials.

\section{Failure and fracture concepts}

The transient thermoelastic stress analysis technique and the associated numerical developments presented earlier can be used to examine the performance of a defect such as a crack located in the asphalt layers of a composite pavement structure. Attention is restricted to the two-dimensional configuration of the pavement which exhibits a state of generalized plane strain. When flaws are present in the asphalt pavement, the conditions that cause such flaws to propagate, in a brittle fashion, can be determined by linear thermoelastic fracture mechanics. Fracture mechanics concept introduces, by analytical considerations, the magnitude and distribution of the stresses around the crack tip of an idealized crack, as a function of the crack size, the elastic properties of the material, and a parameter referred to as stress intensity factor. The stress intensity factor accounts for the manner in which the crack affects the state of stress at the crack tip. The magnitude of the stress intensity factor reflects the state of stress associated with the mode of loading of the crack. For a state of plane strain, two modes of fracture can be identified: the flaw opening mode $\left(K_{\mathrm{I}}\right)$ and the in-plane flaw shearing mode $\left(K_{\mathrm{II}}\right)$ (Fig. 1). The criteria for the propagation of the crack can be assigned by considering experimentally derived critical values of the stress intensity factors $\left(K_{\mathrm{I}}^{c}\right.$ and $\left.K_{\mathrm{II}}^{c}\right)$ individually or in a mixed mode. The critical values of the stress intensity factors are directly related to the fracture toughness of the material in the respective modes.

As shown by Sih and Liebowitz (1965), the classical solution for the elastic displacement field in the vicinity of a crack tip, as shown in Fig. 2, can be expressed as

$$
\begin{aligned}
& \text { [38] } \begin{aligned}
\frac{4 \mu}{\sqrt{r / 2 \pi}} u_{s}= & K_{\mathrm{I}}\{\cos \phi[(2 \gamma-1) \cos \theta / 2-\cos 3 \theta / 2] \\
- & \sin \phi[(2 \gamma+1) \sin \theta / 2-\sin 3 \theta / 2]\} \\
+ & K_{\mathrm{II}}\{\cos \phi[(2 \gamma+3) \sin \theta / 2+\sin 3 \theta / 2] \\
& \quad+\sin \phi[(2 \gamma-3) \cos \theta / 2+\cos 3 \theta / 2]\} \\
\text { [39] } \frac{4 \mu}{\sqrt{r / 2 \pi}} u_{n}= & K_{\mathrm{I}}\{\sin \phi[(2 \gamma-1) \cos \theta / 2-\cos 3 \theta / 2] \\
+ & \cos \phi[(2 \gamma+1) \sin \theta / 2-\sin 3 \theta / 2]\} \\
+ & K_{\mathrm{II}}\{\sin \phi[(2 \gamma+3) \sin \theta / 2+\sin 3 \theta / 2] \\
& \quad-\cos \phi[(2 \gamma-3) \cos \theta / 2+\cos 3 \theta / 2]\}
\end{aligned}
\end{aligned}
$$

where $(r, \theta)$ are the polar coordinates centered at the crack tip and $\phi$ is the inclination of the crack to the $x$ axis. The parameter $\gamma$ is defined as

$$
\text { [40] } \gamma= \begin{cases}3-4 \nu & \text { (plane strain) } \\ (3-\nu) /(1+\nu) & \text { (plane stress) }\end{cases}
$$

Chan et al. (1970) applied the conventional finite element technique to determine the stress intensity factors at crack tips. However, a very substantial refinement of the finite element mesh around the crack tip was required. An accurate value of the stress intensity factor can be obtained by the quarter-point element such as that given by Henshell and Shaw (1975) and Barsoum (1976). The special enriched element with the values of $K_{\mathrm{I}}$ and $K_{\mathrm{II}}$ included in the solution was first formulated by Benzley (1974) and then extended by Gifford and Hilton 


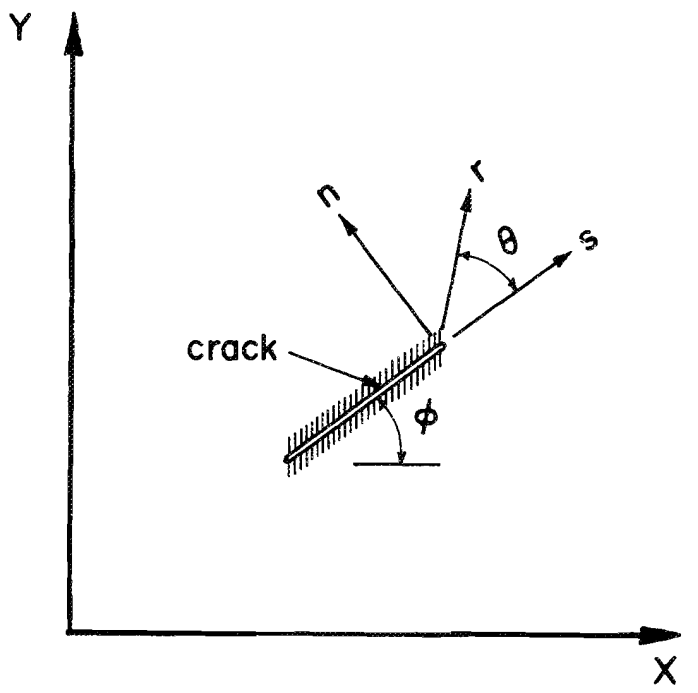

FIG. 2. The local coordinate system at the crack tip.

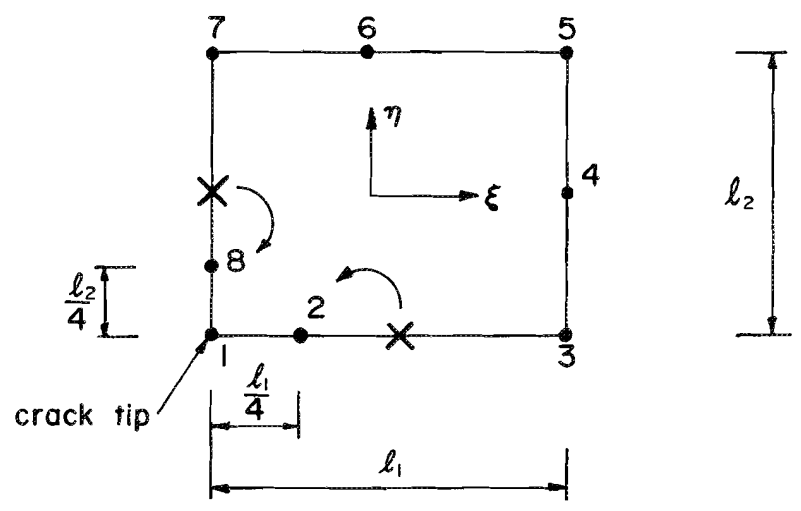

FIG. 3. The quarter-point element.

(1978). Another group of researchers, for example, Tong et al. (1973), Atluri et al. (1975), and Lin and Mar (1976), applied the hybrid element approach to obtain the stress intensity factors.

In this study, the quarter-point element (QPE) is applied to determine the stress intensity factors. The QPE can reproduce the $\sqrt{r}$ type displacement variation in the vicinity of a crack tip (as given by [38] or [39]). This is achieved by placing the mid-nodes adjacent to the crack-tip node at the quarter positions as shown in Fig. 3. In this case, the correct order of stress singularity can be reproduced. Also, the full convergence and conformity of the elements are preserved. To use QPEs efficiently, the following considerations should be observed: $(i)$ the size of the QPE relative to the crack length $(15 \%-25 \%),(i i)$ the number of QPEs enclosing the crack tip should be at least 5 , and (iii) the use of proper transition element's size.

Murti and Valliappan (1986) provide further guidelines to the considerations $(i)-(i i i)$. Numerical values obtained by an efficient use of QPE should be within an error bound of $5 \%$.

Using the QPEs, the stress intensity factors can be evaluated by the nodal displacements along rays emanating from the crack tip and by equating the coefficients of $\sqrt{r}$ in [38] or [39]. For $\phi=0^{\circ}$,
[41] $K_{\mathrm{I}}\left\{\begin{array}{l}(2 \gamma-1) \cos \theta / 2-\cos 3 \theta / 2 \\ (2 \gamma+1) \sin \theta / 2-\sin 3 \theta / 2\end{array}\right\}$

$$
=\frac{4 \mu}{\sqrt{t_{i} / 2 \pi}}\left\{\begin{array}{l}
4 u_{x 2}-u_{x 3}-3 u_{x 1} \\
4 u_{y 2}-u_{y 3}-3 u_{y 1}
\end{array}\right\}
$$

and

$$
\begin{aligned}
& K_{\mathrm{II}}\left\{\begin{array}{l}
-(2 \gamma+3) \sin \theta / 2-\sin 3 \theta / 2 \\
(2 \gamma-3) \cos \theta / 2+\cos 3 \theta / 2
\end{array}\right\} \\
& =\frac{4 \mu}{\sqrt{l_{i} / 2 \pi}}\left\{\begin{array}{l}
4 u_{x 2}-u_{x 3}-3 u_{x 1} \\
4 u_{y 2}-u_{y 3}-3 u_{y 1}
\end{array}\right\}
\end{aligned}
$$

with $l_{i}=l_{1}$ or $l_{2}$ defined in Fig. 2. When $\theta=0^{\circ}$ or $180^{\circ}$, stress intensity factors must be evaluated by the nonzero component from either [41] or [42].

\section{Modelling of low-temperature behaviour of a cracked pavement structure}

The finite element technique presented in the previous section is applied to study the low-temperature performance of a variety of pavement structures which contain overlay and reinforcement features. The basic pavement structure considered in the investigation consists of an asphalt layer underlain sequentially by a compacted base and a subgrade. The asphalt layer contains a crack of finite length. The lateral extent of the pavement structure is considered to be infinite. For the purposes of numerical modelling, however, the pavement structure is assigned a finite lateral dimension. (The lateral dimension $L \simeq 32 h_{2}$, where $h_{2}$ is the thickness of the asphalt layer.) The entire pavement structure is provided with a lateral restraint (Fig. 4). The provision of a lateral restraint, in general, results in the development of the most adverse conditions for the propagation of the crack. When the constraint is remote from the crack location, the far-field stress state induced at the constrained boundary corresponds to that induced in an intact pavement structure, which is biaxially constrained and subjected to thermal loading. Alternatively, the provision of frictionless constraints results in a cracked pavement where cracks occur with a periodicity of $L / h_{2}$. For purposes of numerical computations, it is, of course, necessary to assign specific values for the thickness of the asphalt layer, the compacted base, etc. In this paper the thickness ratios have been assigned by selecting a typical pavement configuration. Certain mechanical and thermomechanical properties of the asphalt layer, the compacted base, and the soil subgrade have also been assigned typical values reported in the literature (see, for example, Kallas and Shook (1977) and PICA $(1982,1984,1987,1990))$. These results are summarized in Table 1.

In certain types of the problems examined in the paper, we shall consider the influence of an asphalt overlay on the thermally induced fracture mechanics of the asphalt layer. To treat this category of problems, it is convenient to specify the thickness of the overlay in relation to the thickness of the asphalt layer. Here again, a typical thickness ratio is investigated. The elastic modulus and the coefficient of thermal contraction of the overlay material are considered to be variables. The paper also treats certain problems in which a reinforcing layer is incorporated between the asphalt overlay and the asphalt layer 


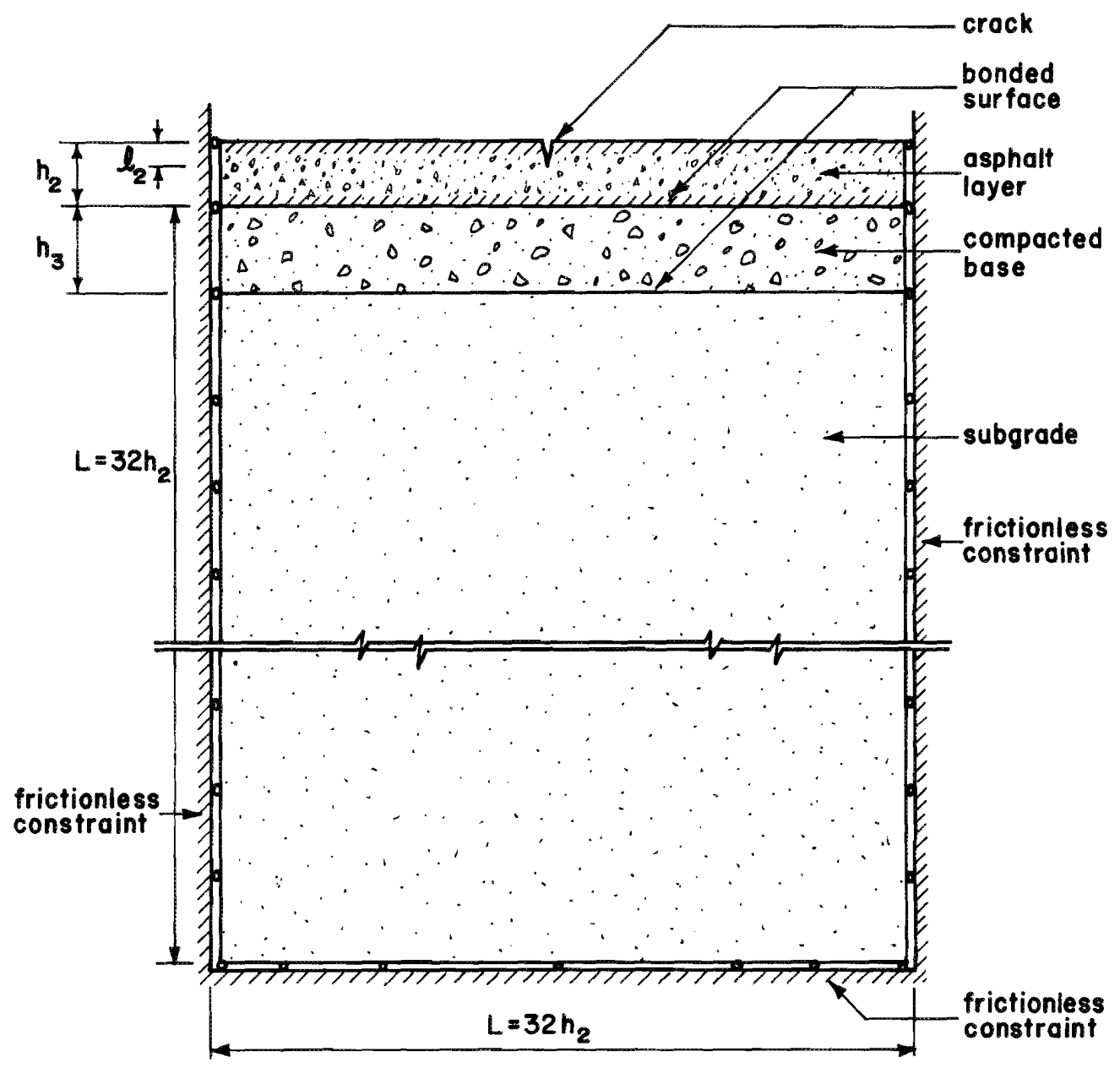

FIG. 4. The pavement model.

TABLE 1. Material parameters utilized in numerical modelling

\begin{tabular}{lcccc}
\hline \multicolumn{1}{c}{$\begin{array}{c}\text { Parameter } \\
\text { (Units) }\end{array}$} & $\begin{array}{c}\text { Asphalt } \\
\text { overlay }\end{array}$ & $\begin{array}{c}\text { Asphalt } \\
\text { layer }\end{array}$ & $\begin{array}{c}\text { Compacted } \\
\text { base }\end{array}$ & $\begin{array}{c}\text { Soil } \\
\text { subgrade }\end{array}$ \\
\hline$G_{i}\left(\mathrm{~N} / \mathrm{m}^{2}\right)$ & Variable & $2.25 \times 10^{7}$ & $1.12 \times 10^{7}$ & $0.45 \times 10^{7}$ \\
$\nu_{\mathrm{i}}$ & 0.3 & 0.3 & 0.3 & 0.3 \\
$\rho_{\mathrm{i}} \mathrm{c}_{\mathrm{i}}\left(\mathrm{J} /\left(\mathrm{m}^{3} \cdot{ }^{\circ} \mathrm{C}\right)\right)$ & $1.5 \times 10^{6}$ & $1.5 \times 10^{6}$ & $4 \times 10^{6}$ & $5 \times 10^{6}$ \\
$k_{i}\left(\mathrm{~J} /\left(\mathrm{m}^{\circ} \cdot \mathrm{s} \cdot{ }^{\circ} \mathrm{C}\right)\right)$ & 1.1 & 1.1 & 1.2 & 1.5 \\
$\alpha_{\mathrm{i}}\left({ }^{\circ} \mathrm{C}\right)^{-1}$ & Variable & $2 \times 10^{-4}$ & $2 \times 10^{-4}$ & $2 \times 10^{-4}$ \\
\hline
\end{tabular}

at the location of the crack. Also, in this case, the elastic stiffness of the reinforcing layer and its thermal contraction properties are considered to be variables in the problem.

Problem I: thermal loading of the cracked asphalt layer

We first examine the case of a cracked asphalt layer of thickness $h_{2}$, which is underlain by a compacted base of thickness $h_{3}$ and a deep soil stratum. The surface crack has a length $l_{2}$. Perfect bond conditions are assumed to exist between the interfaces of the layered pavement structure. The surface of the cracked asphalt layer is subjected to a temperature reduction, which has a specified time history. The temperature at the entire surface of the asphalt layer is assumed to vary with time. Three specific types of variations are considered. In the first category, the temperature at the surface is subjected to a rapid reduction in the form of a step function of time, that is, the surface temperature variation, $T_{\mathrm{s}}(t)$, is given by

[43]

$$
\begin{array}{ll}
T_{\mathrm{s}}(t)=T_{0} ; & t<0 \\
T_{\mathrm{s}}(t)=T_{\mathrm{f}} ; & t>0
\end{array}
$$

In the second example, the surface temperature of the asphalt layer is gradually varied from an initial value of $T_{0}$ to a final value of $T_{\mathrm{f}}$. In particular, the surface temperature is varied in an exponential fashion, that is,

$$
\text { [44] } \begin{array}{ll}
T_{\mathrm{s}}(t)=T_{0} ; & t<0 \\
T_{\mathrm{s}}(t)=T_{0}-\left(T_{0}-T_{\mathrm{f}}\right)\left(1-e^{-t / \tau}\right) ; & t>0
\end{array}
$$

where $\tau$ is a characteristic time. For example, in the numerical 


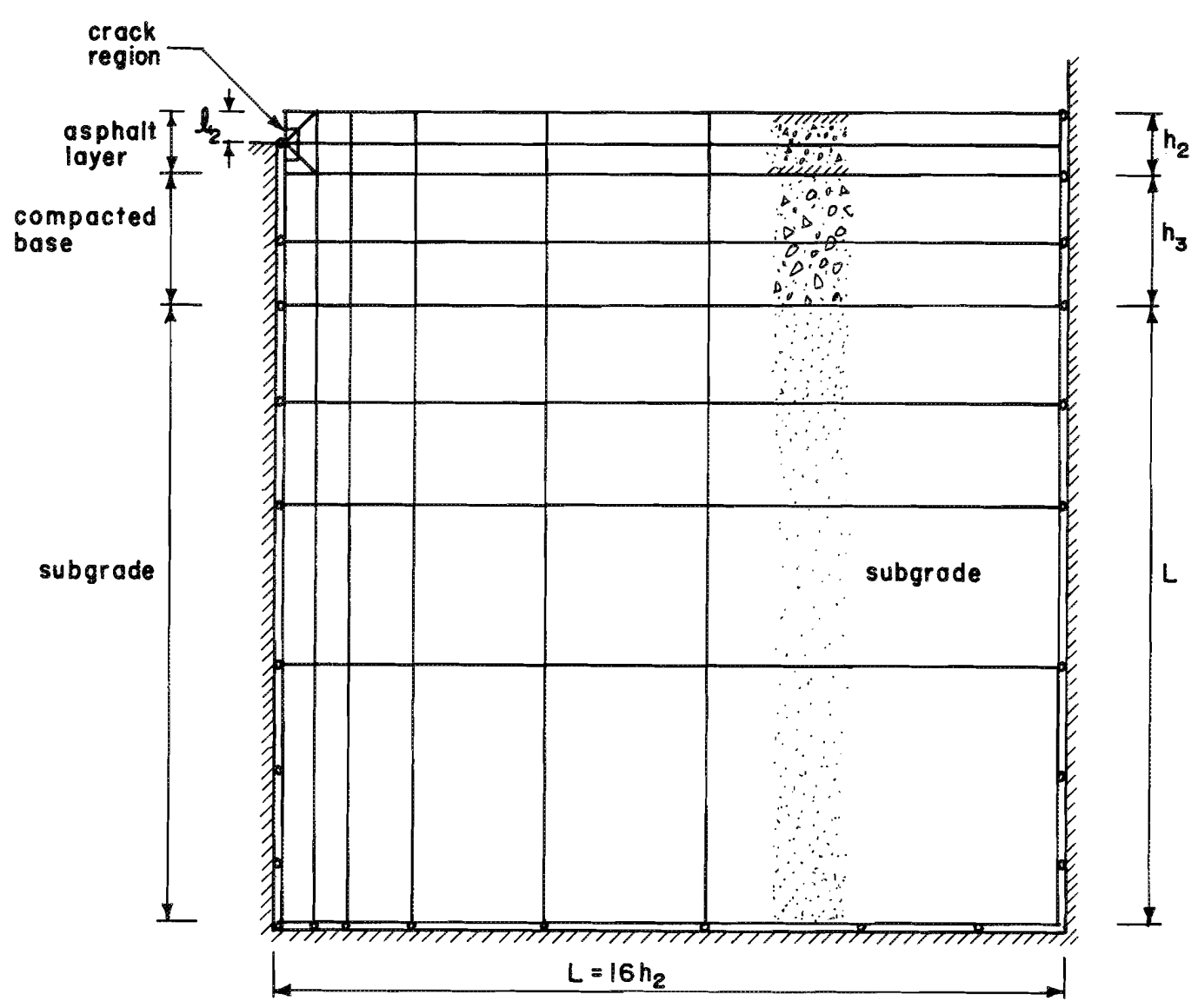

FIG. 5. The finite element discretization of the pavement structure.

computations, the value of $\tau$ is chosen such that, for all practical purposes, the final surface temperature, $T_{\mathrm{f}}$, is reached within $16 \mathrm{~h}$. In the third category, the surface temperature is assumed to vary in a sinusoidal fashion, that is,

$$
\begin{array}{ll}
T_{\mathrm{S}}(t)=T_{0} ; & t<0 \\
T_{\mathrm{S}}(t)=T_{0}-\left(T_{0}-T_{\mathrm{f}}\right) \sin \left(t / t^{*}\right) ; & t>0
\end{array}
$$

where $t^{*}$ is a characteristic time factor. Here again, in the numerical computations the time factor is chosen so that the surface temperature, $T_{\mathrm{f}}$, is reached within $24 \mathrm{~h}$. In all cases, the surfaces of the crack are also assigned the variations described by [43]-[45]. In the numerical investigation, the surfaces of the crack are assigned a zero heat flux condition, corresponding to the state of symmetry. In effect, this boundary condition assumes that the ambient temperatures at the surface of the asphalt layer are not experienced directly by the surfaces of the crack.

The transient finite element analysis can now be performed to evaluate the time-dependent temperature, displacement, and stress fields within the pavement structure. The finite element mesh configuration used in the analysis is shown in Fig. 5. The elements themselves are of the eight-noded quadrilateral type and the special element described in the previous section is incorporated at the crack tip. The results of primary interest to the fracture studies concerns the time-dependent flaw opening mode stress intensity factor at the crack tip. The timedependent variations of the flaw opening mode stress intensity factor at the crack tip, derived for the three variations of surface temperature described by [43], [44], and [45], are shown in Fig. 6. The stress intensity factor is an indicator of the propensity for the propagation of the crack. The higher the value of the stress intensity factor the greater the susceptibility for crack propagation. The following observations can be made with regard to the above results. When the surface of the asphalt layer is subjected to a time-dependent variation in the surface temperature, the stress amplification, as indicated by the flaw opening mode stress intensity factor, exhibits a corresponding time-dependent response. Owing to the heat conduction process in the pavement system, the stress amplification exhibits a time lag. The magnitude of the time lag depends on the thermal conductivity parameters of the various components of the pavement structure. Approximately the same maximum value of the stress intensity factor at the crack tip is attained for all three variations in the surface temperature of the asphalt layer prescribed by [43]-[45]. This observation suggests that the maximum value of the stress intensity factor at the crack tip can be obtained by specifying the surface temperature reduction simply as a step function of time. Therefore in all subsequent problems, the influence of a temperature reduction at the surface of the asphalt layer is accounted for by specifying a step function type variation, in which $T_{\mathrm{f}}$ is assumed to be the minimum surface temperature encountered in a temperature history. The flaw opening mode stress intensity factor at the tip of the crack located in the asphalt layer, $K_{1}^{(0)}$, (without the modifying influence of an overlay or rein- 

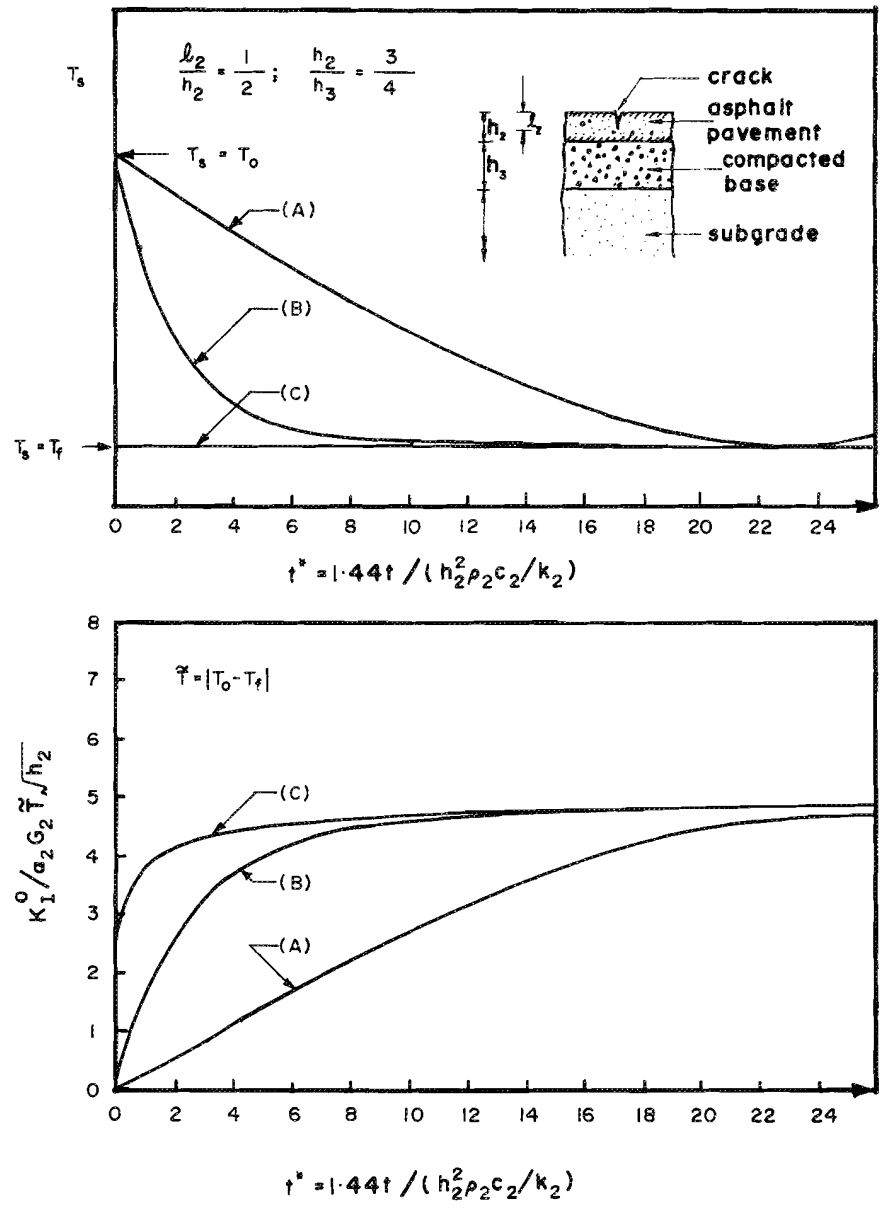

FIG. 6. (a) Time-dependent variation of temperature at the surface of the pavement structure $(\mathrm{A}$ - sinusoidal variation of temperature with time, B - exponential variation of temperature with time, and C - step function variation of temperature with time); (b) timedependent variation of the flaw opening mode stress intensity factor at the crack tip.

forcement) is the parameter of primary interest. The manner in which $K_{1}^{(0)}$ is influenced by the crack dimension $l_{2} / h_{2}$ is illustrated in Fig. 7.

\section{Problem II: influence of an uncracked overlay}

As the second example, we consider the problem of an asphalt pavement structure with a surface crack of depth $l_{2}$. An asphalt overlay is constructed on the cracked pavement structure. The newly constructed overlay exhibits complete continuity at the interface of the overlay and the cracked asphalt layer. It is further assumed that during the construction of the new asphalt overlay there is no extension of the existing crack. Finally, we consider the situation where the asphalt overlay remains intact (no fracture or delaminations) during any thermal loading of the pavement system. As established in the previous example, the effect of a reduction in the surface temperature of the pavement structure on the fracture behaviour of the asphalt layer can be established by considering the extreme situation where temperature is varied in the form of a step function. Following this observation, we consider the situation where the surface of the asphalt overlay is subjected to the temperature reduction defined by [43].
Figure 8 shows the manner in which the maximum value of the flaw opening mode stress intensity factor at the tip of the crack located in the asphalt layer is influenced by the depth of the crack $\left(l_{2}\right)$ and the thermoelastic properties of the asphalt layer-overlay system. These results are normalized with respect to the equivalent stress intensity factor for the situation where the asphalt overlay is absent. These results indicate that the presence of the overlay tends to attenuate the stress intensity factor at the crack tip. This effect, which occurs irrespective of the thermoelastic mismatch between the asphalt layer and the overlay, is in essence an insulation effect due to the presence of the overlay. Figure 9 illustrates a normalized plot of the stress intensity factor at the crack tip in the asphalt layer and its variation with the elasticity mismatch between the overlay and the asphalt layer and the depth of the crack. It is noted that for the pavement geometry examined in the paper, the stress intensity factor appears to be relatively insensitive to the mismatch in the thermal expansion properties between the overlay and the asphalt layer (i.e., $\left.10^{-2}<\left(\alpha_{1} / \alpha_{2}\right)<10^{2}\right)$.

\section{Problem III: influence of a cracked overlay}

In the previous example, we have assumed that the initial crack in the asphalt layer does not extend itself to the newly placed overlay during its construction. We now examine the situation where cracking exists both in the asphalt layer and in the newly placed overlay (Fig. 10). The surface of the overlay is again subjected to the temperature reduction defined by [43]. In this instance, the flaw opening mode stress intensity factors need to be determined for crack tips located both within the overlay $\left(K_{1}^{(1)}\right)$ and within the asphalt layer $\left(K_{1}^{(2)}\right)$. Figures 11 and 12 illustrate the manner in which the normalized stress intensity factor, $K_{\mathrm{I}}^{(2)} / K_{\mathrm{I}}^{(0)}$, at the crack tip in the asphalt layer is influenced by $(i)$ the mismatch in the elastic shear modulus and the coefficient of thermal contraction between the asphalt layer and the overlay and (ii) the relative crack lengths in the overlay and the asphalt layer. Similar results can also be developed for the normalized flaw opening mode stress intensity factor at crack tips located in the overlay. It is, however, more appropriate to identify the relative influences of the nondimensional parameters $G_{1} / G_{2}, \alpha_{1} / \alpha_{2}$, $l_{1} / h_{1}$, and $l_{2} / h_{2}$ on the magnitudes of the flaw opening mode stress intensity factors, $K_{Y}^{(1)}$ and $K_{I}^{(2)}$. Figure 13 illustrates the relative combinations of the material and geometric parameters for which either $K_{1}^{(1)}>K_{1}^{(2)}$ or $K_{I}^{(1)}<K_{1}^{(2)}$. It is evident that the potential for the propagation of the crack either into the overlay or into the asphalt layer is significantly influenced by mismatch in the thermal and stiffness properties between the asphalt layer and the overlay.

\section{Problem IV: influence of a reinforcing layer and uncracked overlay}

In recent years, several investigators have advocated the use of advanced synthetic reinforcing materials for the purposes of suppressing crack propagation in both the pavement structure and in a newly placed overlay. The reinforcing layer, which is usually a geogrid structure, is placed at the interface between the cracked asphalt pavement and the overlay. In this section we examine the manner in which the crack extension can be suppressed by the presence of a reinforcing layer. As the basic model, we consider the influence of a layer of reinforcement that is completely bonded to both the asphalt layer and the overlay. The reinforcement is modelled as a plane 


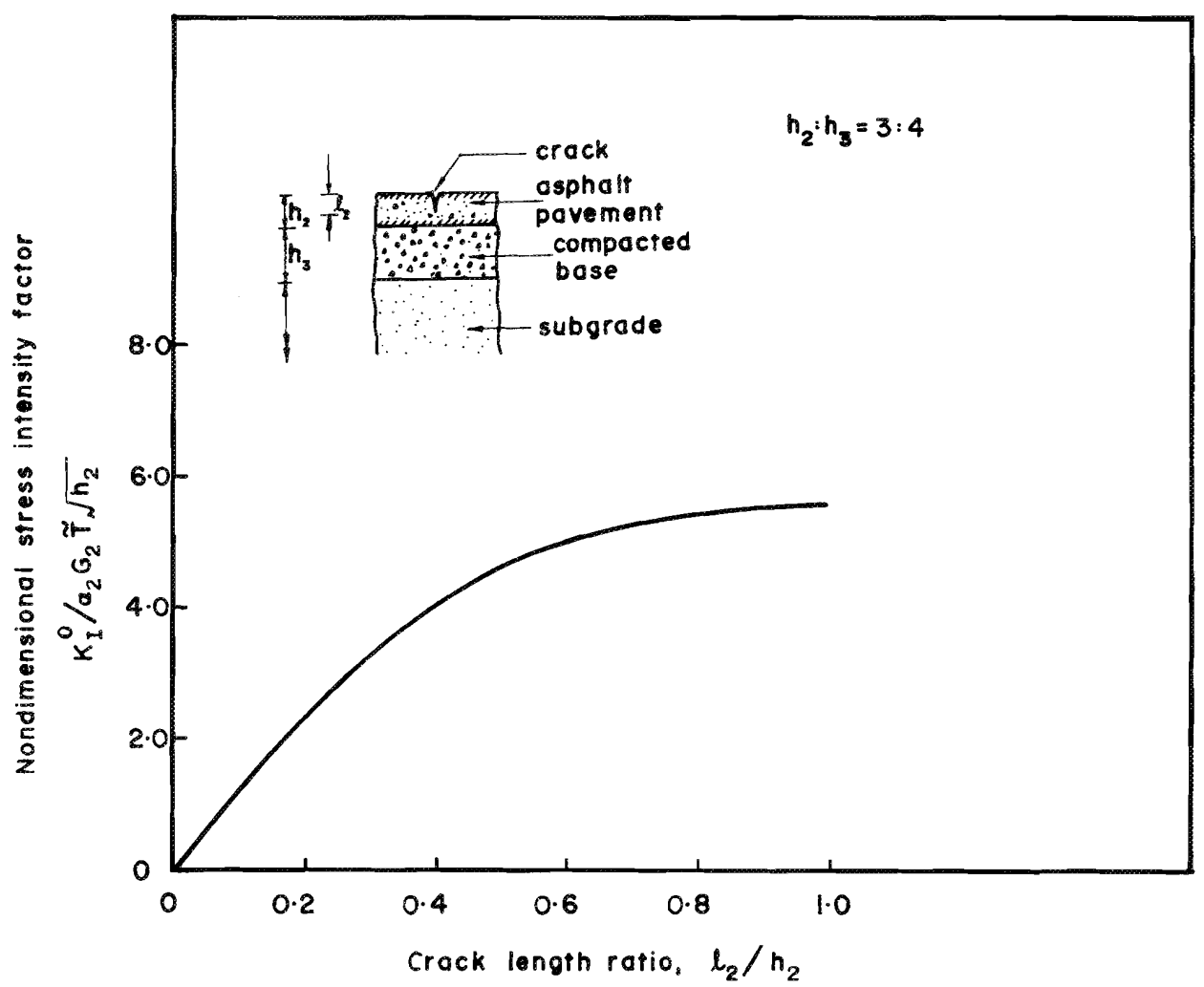

FIG. 7. Influence of the crack length on the flaw opening mode stress intensity factor at the crack tip.

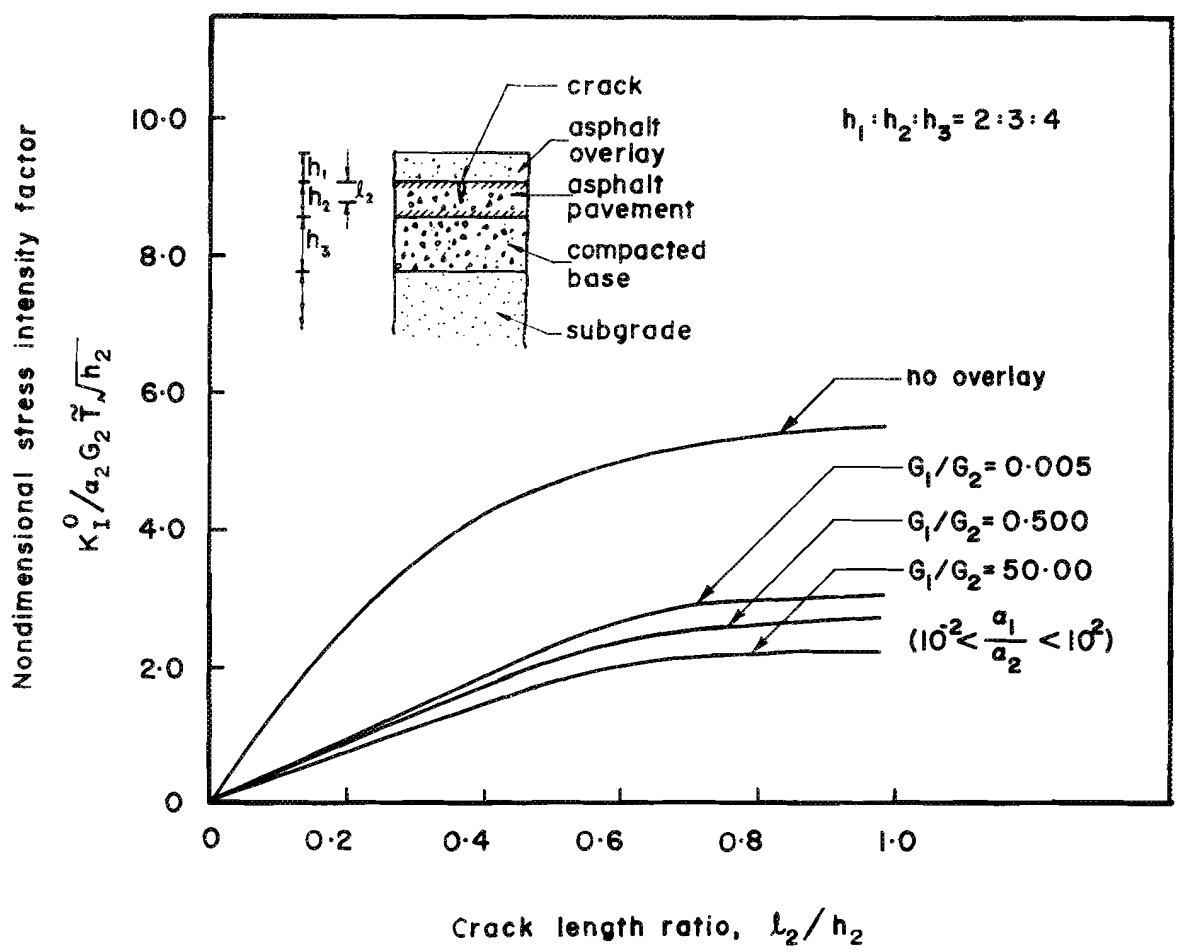

FIG. 8. Flaw opening mode stress intensity factor at the crack tip: influence of an overlay.

extensional element which possesses effective elastic stiffness characterized by an elastic modulus, $E^{*}$, and a cross-sectional area, $A$. Accordingly, no account is made for possible threedimensional effects that may be present in an actual geogrid reinforcing layer. The coefficient of linear contraction is defined by $\alpha^{*}$. The modelling considers the situation where a crack exists only in the asphalt layer and the overlay is intact. The interface between the asphalt layer and the overlay is fully 


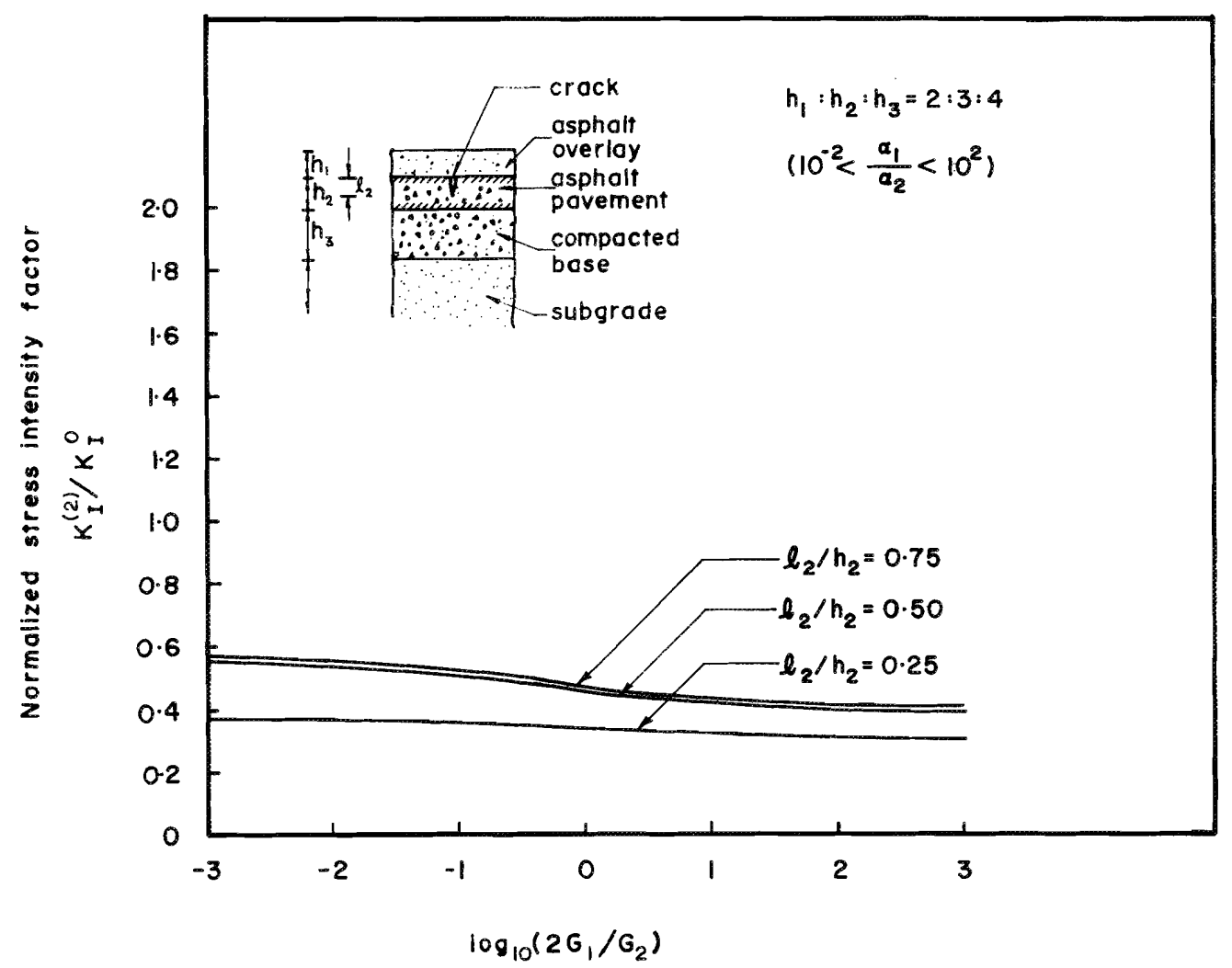

FIG. 9. Variations of the normalized flaw opening mode stress intensity factor, $K_{\mathrm{I}}^{(2)} / K_{\mathrm{I}}^{(0)}$, at the crack tip: influence of the crack length and the overlay-to-pavement modular ratio, $G_{1} / G_{2}$.

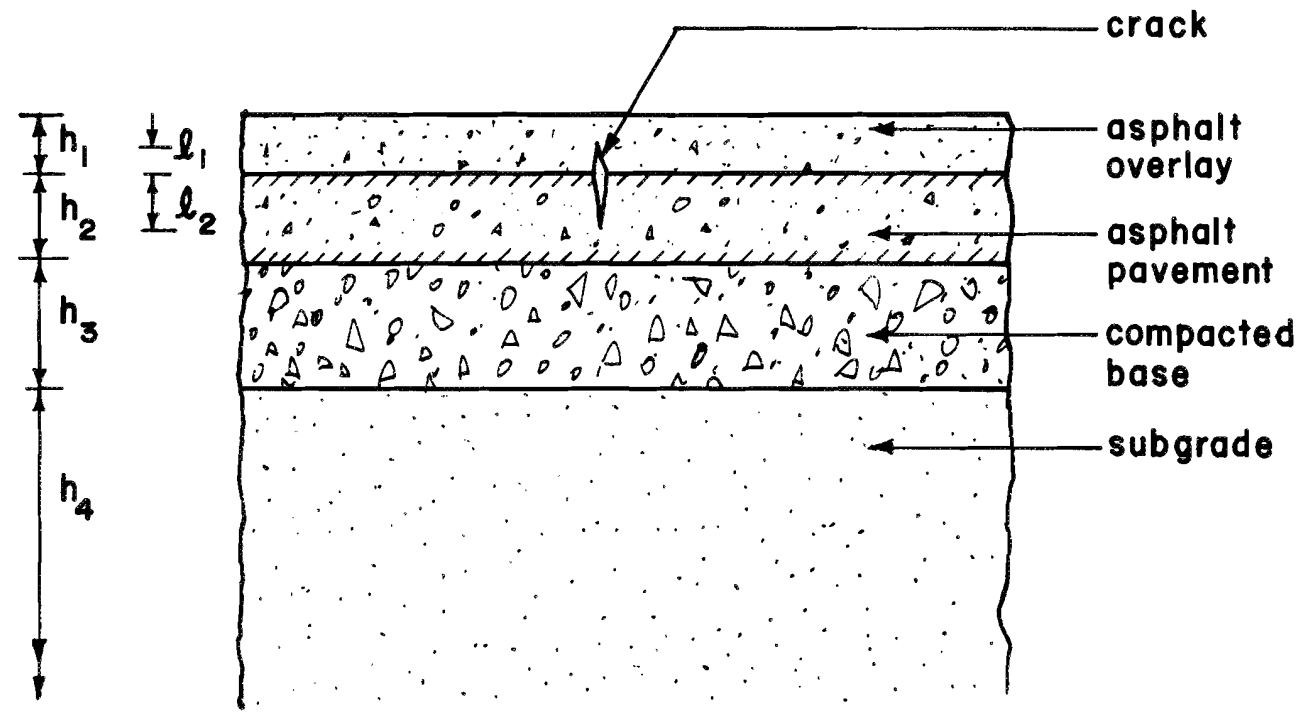

FIG. 10. Modelling of crack extension into the overlay.

bonded and maintains continuity with the reinforcement. The numerical scheme is applied to examine the influence of the reinforcement in attenuating the flaw opening mode stress intensity factor at the crack tip. Figures $14-16$ illustrate the variation of the normalized stress intensity factor, $K_{I}^{(2)} / K_{1}^{(0)}$, at the crack tip for various choices of the reinforcing layerasphalt pavement relative stiffness parameter, $18 E^{*} A / G_{2} h_{2}^{2}$, and the reinforcement-pavement thermal contraction ratio, $a^{*} / \alpha_{2}$. It is evident that for $\alpha^{*} / \alpha_{2}$ in the range $10^{-2}-1.0$ and for $\alpha_{1} / \alpha_{2}$ in the range $10^{-2}-10^{3}$, the reinforcement has only a marginal effect in decreasing the stress intensity factor at the crack tip located in the asphalt layer.

\section{Conclusions}

This paper presents the modelling of the low-temperature thermomechanical performance of a pavement structure by transient thermoelastic stress analysis. The linear thermoelas- 


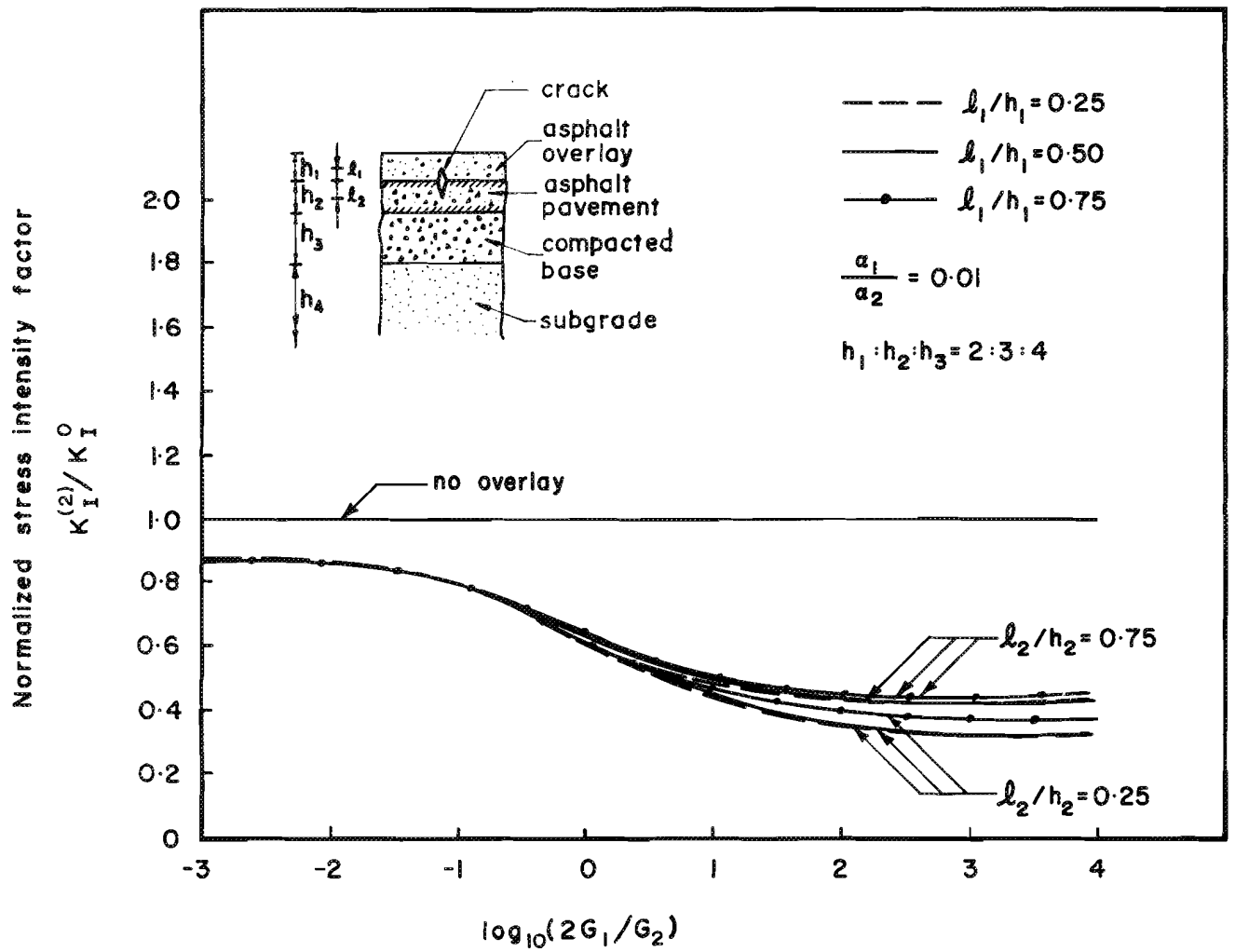

FIG. 11. Variations of the normalized flaw opening mode stress intensity factor, $K_{\mathrm{I}}^{(2)} / K_{1}^{(0)}$, at the crack tip located in the asphalt layer: influence of the crack length and the overlay-to-pavement modular ratio, $G_{1} / G_{2}$.

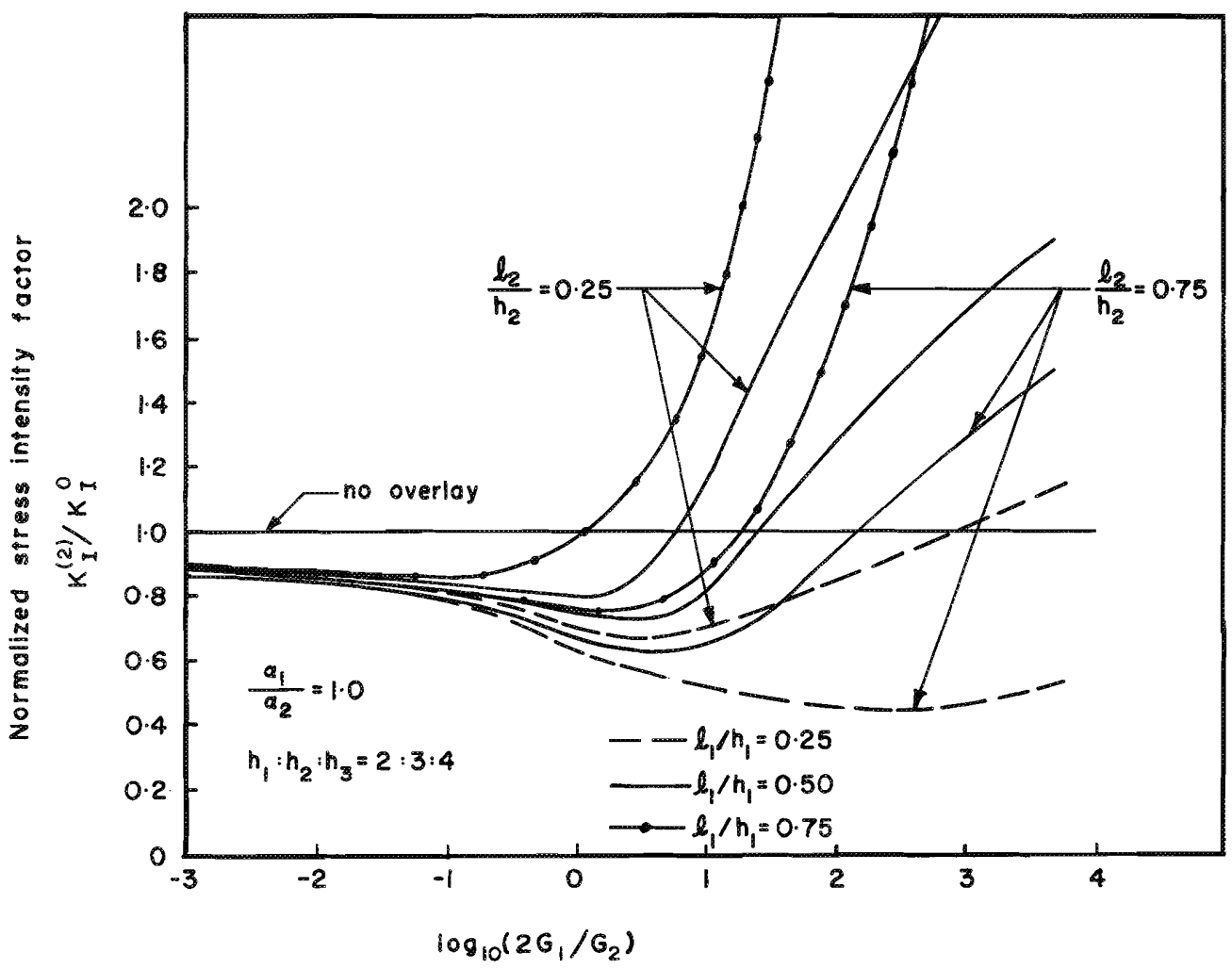

FIG. 12. Variations of the normalized flaw opening mode stress intensity factor, $K_{\mathrm{I}}^{(2)} / K_{\mathrm{I}}^{(0)}$, at the crack tip located in the asphalt layer: influence of the crack length and the overlay-to-pavement modular ratio, $G_{1} / G_{2}$. 


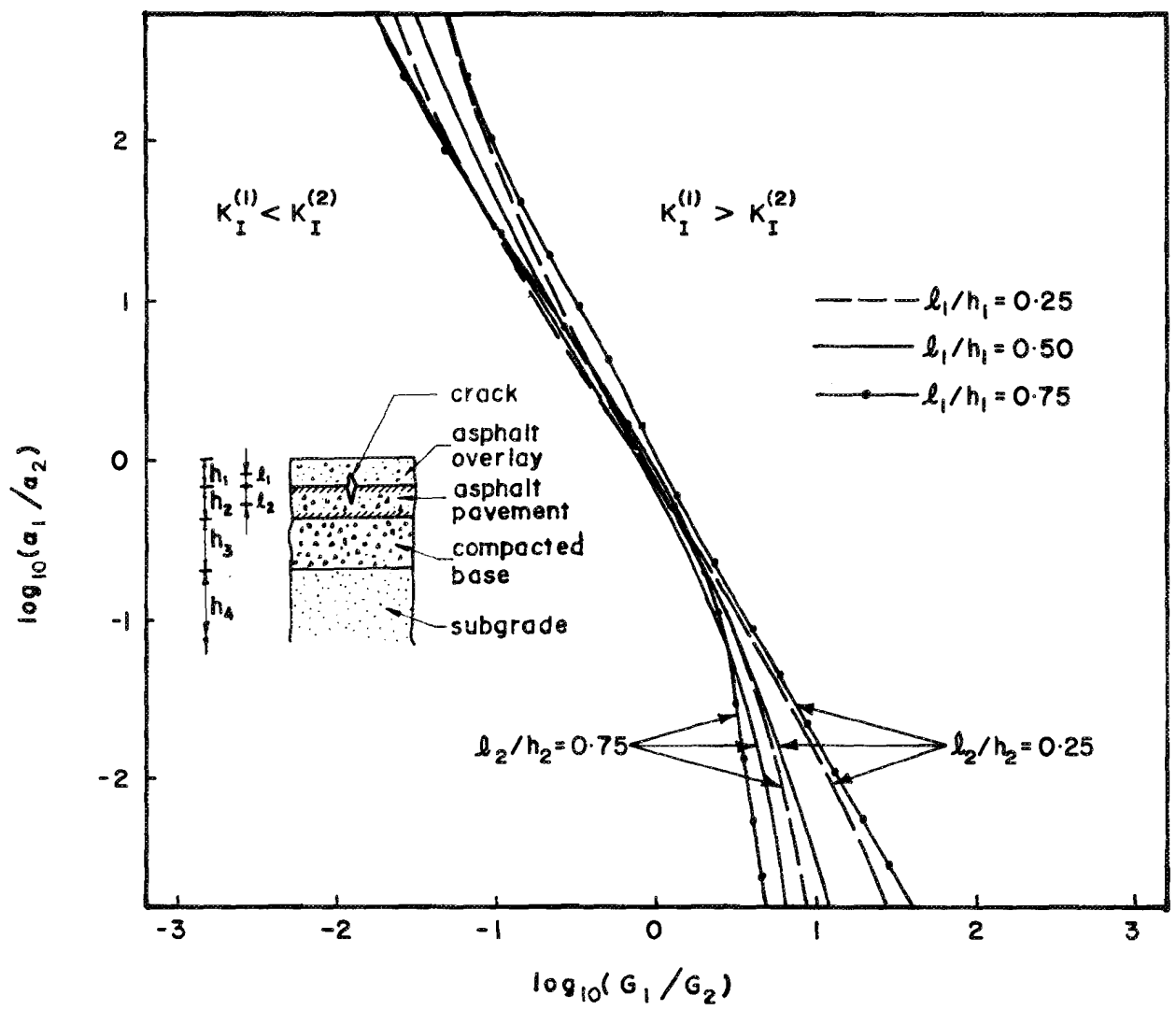

FIG. 13. Relative magnitudes of the flaw opening mode stress intensity factors for crack tips located in the asphalt pavement and the overlay. $\left(\alpha_{1} / \alpha_{2}=\right.$ thermal coefficient ratio; $G_{1} / G_{2}=$ overlay-to-pavement modular ratio.)

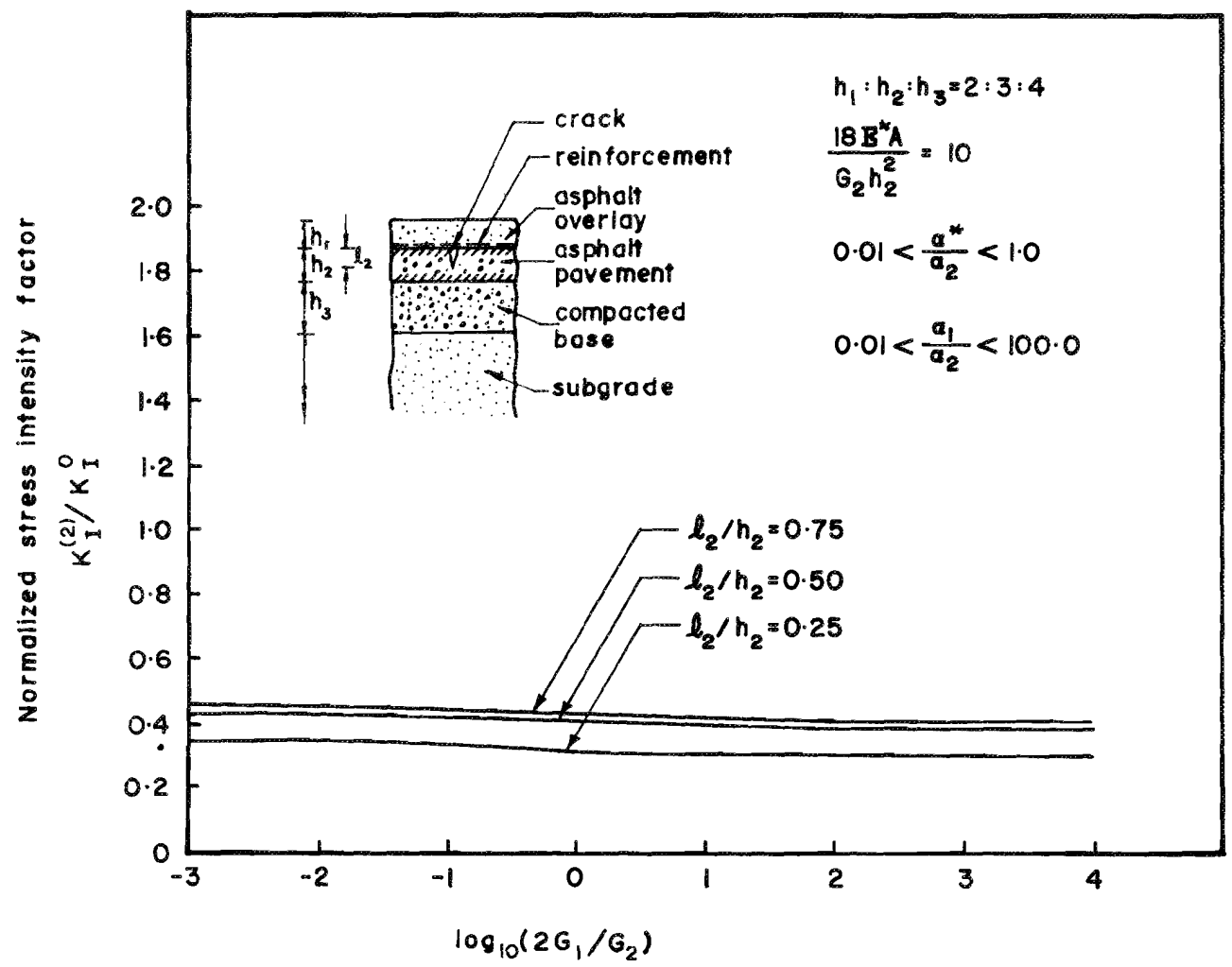

Fig. 14. Influence of a reinforcing layer on the flaw opening mode stress intensity factor at the crack tip. 


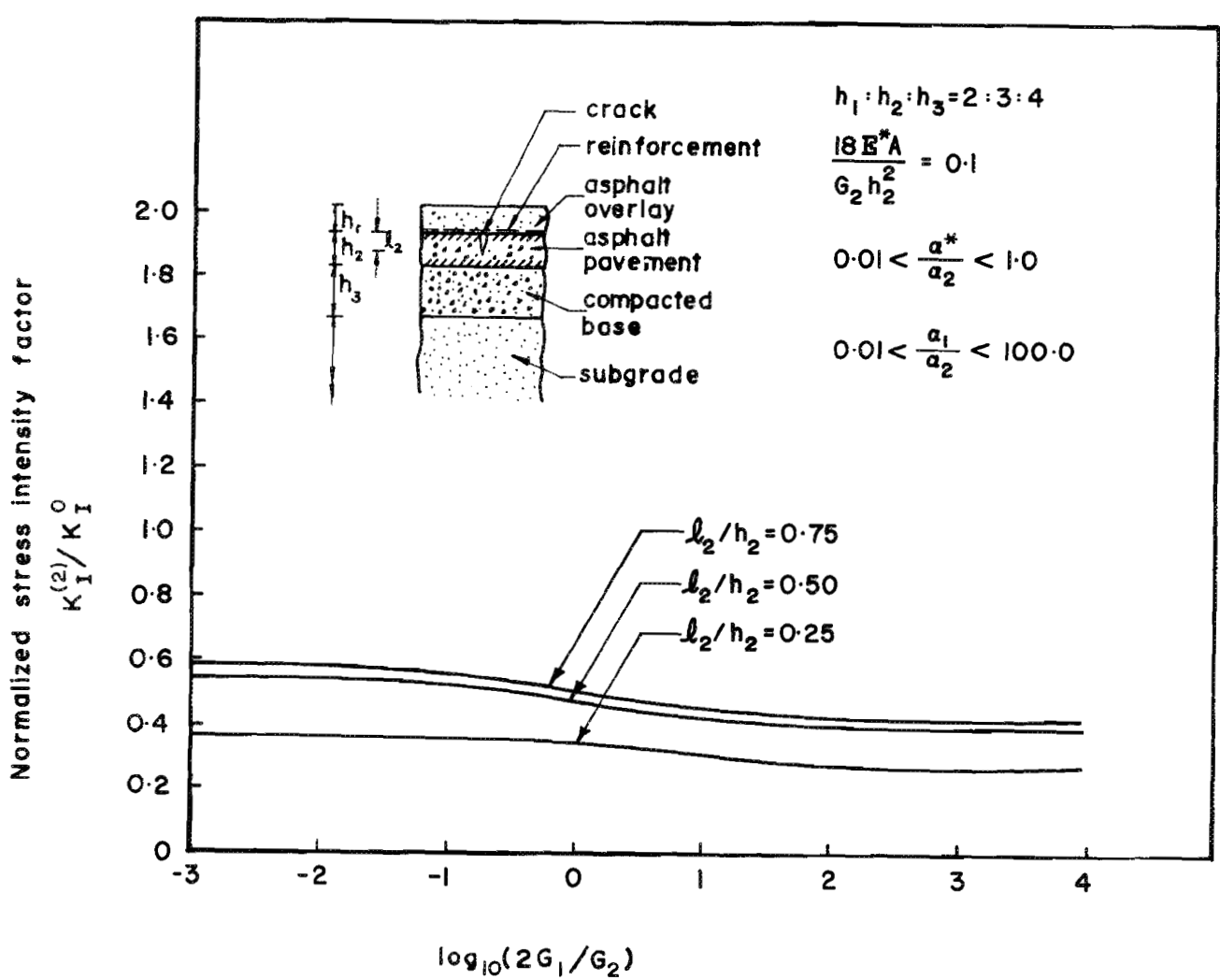

FIG. 15. Influence of a reinforcing layer on the flaw opening mode stress intensity factor at the crack tip.

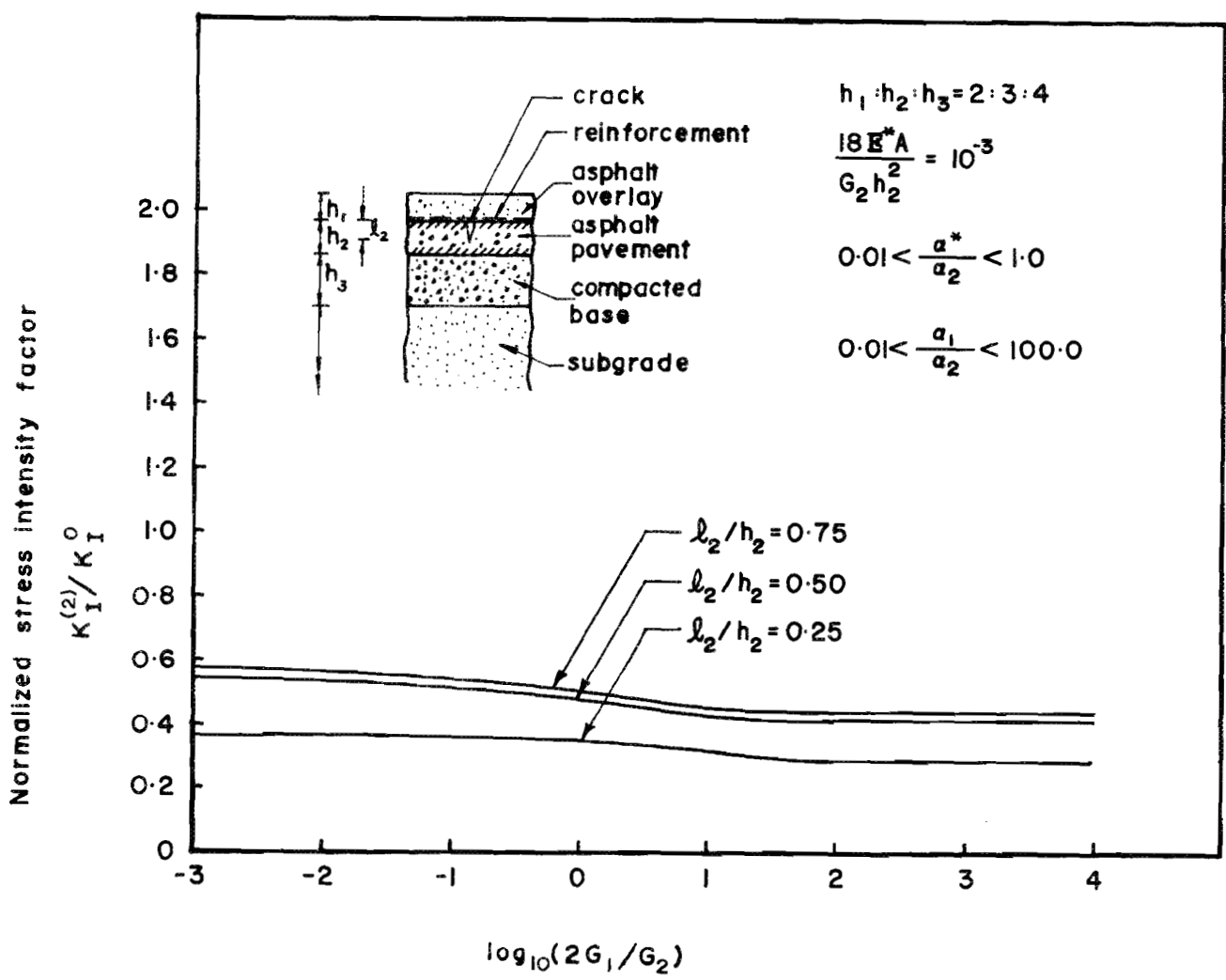

FIG. 16. Influence of a reinforcing layer on the flaw opening mode stress intensity factor at the crack tip. 


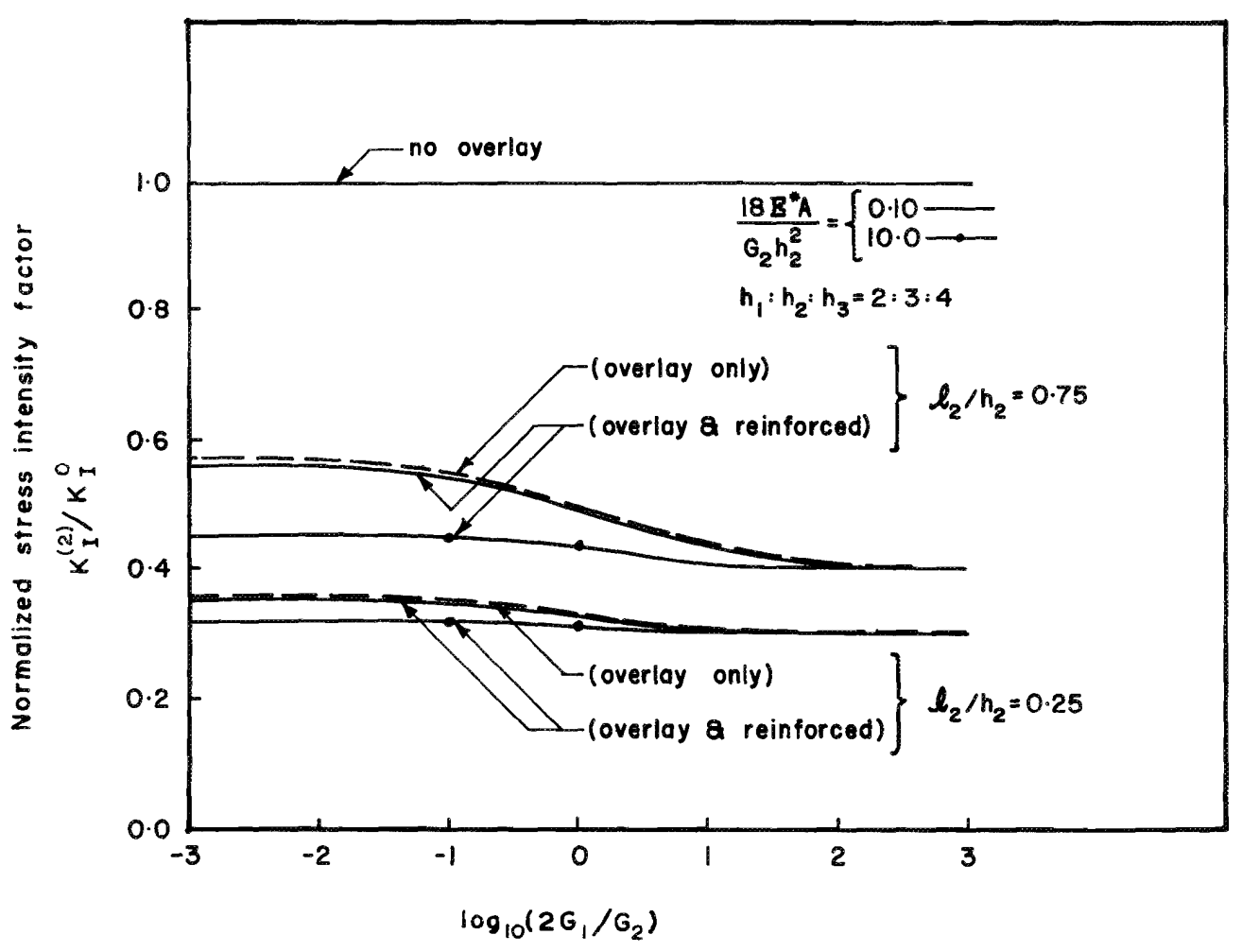

Fig. 17. A comparison of the influence of the overlay and a reinforcing layer on the flaw opening mode stress intensity factor at the crack tip.

tic modelling of the pavement response is intended to provide a first approximation to the more complicated time- and temperature-dependent mechanical and thermal behaviour of asphalt pavement materials. The finite element modelling can be used quite successfully to examine the behaviour of flaws, which are present at the surface of the asphalt layer. In particular, transient thermoelastic finite element analysis can be combined with a crack model to examine the manner in which low-temperature effects accentuate the flaw opening mode stress intensity factor at the crack tip. The theoretical developments and the associated numerical schemes are used to examine the low-temperature-induced enhancement of fracture potential of surface flaws. For purposes of illustration, the numerical results have been developed for a pavement structure in which the thicknesses of the layers are assigned typical proportions. The results are nevertheless indicative of the responses that can be displayed by typical pavement structures. The basic observations of the investigation are summarized as follows:

(i) In general, pavement structures can be subjected to low temperatures exhibiting time-dependent variations. The overall effects of such time-dependent variations can be assessed by subjecting the surface of the pavement structure to a stepfunction temperature reduction. The magnitude of the temperature reduction is set equal to the minimum surface temperature encountered in the time-dependent variation.

(ii) The tendency for propagation of an existing flaw in an asphalt pavement is characterized by the amplification of the flaw opening mode stress intensity factor at the crack tip. It is found that in the case of a pavement structure in which the asphalt layer contains a surface crack, the flaw opening mode stress intensity factor is influenced by a number of parameters, including the crack size, the temperature reduction, and the thermomechanical properties of the asphalt layer.

(iii) The introduction of an asphalt overlay has basically two beneficial effects in terms of attenuating the stress intensity factor at the crack tip in the asphalt layer. First, the overlay acts as an insulating layer, which decreases the low-temperature-induced deformations of the asphalt layer and which in turn reduces the magnitude of the stress intensity factor. This insulating influence is borne out by the fact that even for overlays with relatively low elastic modulus, the maximum stress intensity factor at the crack tip is reduced by nearly $100 \%$. A further reduction occurs owing to the bridging action of the overlay at the existing flaw.

(iv) In the instance where a reinforcing layer is incorporated at the interface between the asphalt layer and the asphalt overlay, additional bridging action is provided by the reinforcement. This in turn results in the reduction of the stress intensity factor at the crack tip within the asphalt layer. The efficiency of the reinforcing layer depends invariably on a number of factors, including the relative thermoelastic and stiffness mismatch between both the asphalt layer-asphalt overlay system and the asphalt layer-reinforcing layer system. The analytical modelling of the problem assumes that the reinforcing layer is in an extended configuration and is capable of providing the bridging action across the crack region during a temperature reduction. The relative contributions of the asphalt overlay and the reinforcing layer to the attenuation of the flaw opening mode stress intensity factor at the crack tip located in the asphalt layer are illustrated in Fig. 17.

(v) In the instance where the crack extends or reflects to the 
asphalt overlay, two stress intensity factors are encountered; one corresponding to the crack tip located in the asphalt layer and the other corresponding to the crack tip located in the overlay. The tendency for the extension of the crack either into the overlay or into the asphalt layer will be governed by the relative magnitudes of the stress intensity factors at the two locations. In general, however, the conditions for crack propagation depend upon the magnitudes of $K_{\mathrm{I}}^{(i)} / K_{\mathrm{Ic}}^{(i)}$, where $i=1$ corresponds to the overlay and $i=2$ corresponds to the asphalt layer and $K_{\text {Ic }}^{(i)}$ are the critical fracture toughness measures for the respective materials. Some insight into the mode of crack extension can be gained by comparing the relative magnitudes of $K_{Y}^{(i)}$. It is found that the direction of propagation of the crack is governed by the mismatch in the thermal contraction properties and the shear moduli between the asphalt layer and the overlay.

\section{Acknowledgements}

The work described in this paper was supported by a research contract awarded by the Pavement Research Branch of the Ministry of Transportation of Ontario and by a research grant (A3866) awarded by the Natural Sciences and Engineering Research Council of Canada. The authors are grateful to the referees for their valuable comments.

AsPhalt INSTITUTE. 1981. Design techniques to minimize lowtemperature asphalt pavement transverse cracking. Report No. 81-1, RR-81-1, Asphalt Institute, College Park, MD.

Atluri, S. N., Kobayashy, A. S., and NaKagaKI, M. 1975. An assumed displacement hybrid finite element model for linear fracture mechanics. International Journal of Fracture, 11: 257-271.

BARsoum, R. S. 1976. Use of isoparametric finite elements in linear fracture mechanics. International Journal for Numerical Methods in Engineering, 10: 25-37.

BENZLEY, S. F. 1974. Representation of singularities with isoparametric finite elements. International Journal for Numerical Methods in Engineering, 8: 537-545.

CARLSON, D. E. 1972. Linear thermoelasticity. In Mechanics of solids II. Handbuch der Physik. Edited by S. Flugge. SpringerVerlag, Berlin, West Germany. pp. 297-345.

CARPENTER, S. H. 1976. Thermal susceptibility: its causes and effect on pavement cracking. Transportation Research Record 616, Transportation Research Board, Washington, DC, pp. 89-91.

Carpenter, S. H., and LyTtion, R. L. 1978. Procedure for predicting occurrence and spacing of thermal susceptibility cracking in flexible pavements. Transportation Research Record 671, Transportation Research Board, Washington, DC, pp. 39-46.

Carpenter, S. H., LytTon, R. L., and EPPS, J. A. 1975. Pavement cracking in west Texas due to freeze-thaw cycling. Transportation Research Record 532, Transportation Research Board, Washington, DC, pp. 1-13.

Chan, S. K., Tuba, I. S., and Wilson, W. K. 1970. On finite element method in linear fracture mechanics. Engineering Fracture Mechanics, 2: 1- 17 .
GifFord, L. N., and HiLton, P. D. 1978. Stress intensity factors by enriched finite elements. Engineering Fracture Mechanics, 10: $485-496$.

HAAS, R. C. G. 1970. Low-temperature pavement cracking in Canada: the problem and its treatment. Proceedings of the Canadian Good Roads Association, Montréal, Que.

HAAS, R. C. G., and TOPPER, T. H. 1968. Thermal fracture phenomena in bituminous surfaces. Special Report 101, Highway Research Board, Washington, DC, pp. 136-153.

HENSHELl, R. D., and SHAW, K. G. 1975. Crack-tip finite elements are unnecessary. International Journal for Numerical Methods in Engineering, 9: 495-507.

Humphreys, J. S., and MarTin, C. J. 1963. Determination of transient stresses in a slab with temperature dependent viscoelastic properties. Transactions of the Society of Rheology, 7: 155-170.

Kallas, B. F., and SHOoK, J. F. 1977. San Diego County Experimental Base Project, Research Report RR-77-1, Asphalt Institute, College Park, MD.

Kovalenko, A. D. 1969. Thermoelasticity. Wolters-Noordhoff Publishing Co., Groningen, The Netherlands.

LIN, K. Y., and MAR, J. W. 1976. Finite element analysis of a stress intensity factor for cracks at a bi-material interface. International Journal of Fracture, 12: 521-531.

MCLEOD, N. W. 1970. Influence of hardness of asphalt cement on low-temperature transverse pavement cracking. Proceedings of the Canadian Good Roads Association, Montréal, Que.

MurTi, V., and ValliapPan, S. 1986. A universal optimum quarter point element. Engineering Fracture Mechanics, 25: 237-258.

PICA. 1982. Paving in cold areas. Proceedings of the MiniWorkshop, Canada/Japan Science and Technology Consultations, Vancouver, B.C.

1984. Paving in cold areas. Proceedings of the MiniWorkshop, Canada/Japan Science and Technology Consultations, Tsukuba, Japan.

1987. Paving in cold areas. Proceedings of the MiniWorkshop, Canada/Japan Science and Technology Consultations, Ottawa, Ont

1990. Paving in cold areas. Proceedings of the MiniWorkshop, Canada/Japan Science and Technology Consultations, Sapporo, Japan.

Shahin, M. Y., and McCullough, B. F. 1972. Prediction of lowtemperature and thermal-fatigue cracking in flexible pavements. Research Report 123-144, Centre for Highway Research, University of Texas, Austin, TX.

SiH, G. C., and LiEBowitz, H. 1968. Mathematical theories of brittle fracture. In Fracture. Edited by H. Liebowitz. Academic Press, New York, NY. Vol. II, pp. 67-190.

Sugawara, T., Kubo, H., and Moriyoshi, A. 1982. Low temperature cracking of asphalt pavements. In Paving in cold areas. Proceedings of Canada/Japan Science and Technology Consultations, Vancouver, B.C., Vol. I, pp. 3-42.

Tong, P., Pian, T. H. H., and LasRY, S. J. 1973. A hybrid element approach to crack problems in plane elasticity. International Journal for Numerical Methods in Engineering, 7: 297-308.

ZIENKIEWICZ, O. C. 1977. The finite element method in engineering science. McGraw-Hill, New York, NY. 